\title{
Najstarszy inwentarz zbrojowni nieświeskiej (1569)
}

The Oldest Inventory of the Nieśwież Armoury (1569) Abstrakt: Artykuł omawia zbrojownię w Nie-
świeżu (własność Radziwiłłów) w połowie XVI w.
Podstawowym źródłem do tego zagadnienia jest
inwentarz sporządzony w 1569 r. Wymienia on po-
nad 500 elementów uzbrojenia. Wśród nich 220
egzemplarzy uzbrojenia ochronnego, I26 egzem-
plarzy uzbrojenia zaczepnego (wśród nich 47 razy broń drzewcową) oraz iıs elementów rzędu końskiego i oporządzenia jeździeckiego. W 1569 r. w zbrojowni radziwiłłowskiej spisano między innymi zbroje płytowe, hełmy, tarcze, włócznie, halabardy, ręczną broń palną, a także włoskie, niemieckie i orientalne siodła $\mathrm{z}$ aksamitnym lub skórzanym, w tym kurdybanowym, pokryciem.

Słowa kluczowe: Rzeczpospolita Obojga Narodów, zbrojownia radziwiłłowska, zamek w Nieświeżu, inwentarz z I569 r.

Rozwój łódzkiego ośrodka bronioznawczego (łódzkiej szkoły bronioznawczej) przebiegał nie tylko w oparciu o szerokie i efektywne badania archeologów skupionych wokół ośrodków: „panowskiego” i uniwersyteckiego (Kajzer 2013: 16-17; Głosek 2020: 16-26). Równolegle zagadnieniami tymi interesowali się także historycy, szukając własnej metody badawczej i opierając się głównie na źródłach pisanych, takich jak rachunki królewskie i wojskowe, inwentarze, umowy handlowe, statuty cechowe, a szczególnie opisy sztuk mistrzowskich (Szymczak 2008: 6).

Do typowych źródeł gospodarczych można zaliczyć inwentarze, a wśród nich dość unikalny zbiór inwentarzy rezydencji radziwiłłowskich. Spisano w nich tysiące przedmiotów znajdujących się w siedzibach rodu, a jednym z ciekawszych jest spis z $1569 \mathrm{r}$. Wówczas po raz pierwszy uwzględniono wśród spisywanego stanu posiadania uzbrojenie przechowywane w Nieświeżu. Jest to dowód obecności ogromnej kolekcji w miejscu jej wytworzenia (zgromadzenia) już w połowie XVI w. O ile bowiem stosunkowo łatwo określić (szczególnie w odniesieniu do największych dzieł sztuki), co znajdowało się w zbrojowni nieświeskiej, o tyle doprecyzowanie kiedy się w niej pojawiło i w jakiej skali, nie jest już tak proste.

W powszechnym mniemaniu uzbrojenie radziwiłłowskie kojarzone jest tylko i wyłącznie z tak zwaną zbrojownią nieświeską. Tymczasem każda z gałęzi licznego 
i wpływowego rodu posiadała własny zbiór przedmiotów luksusowych, wśród których uzbrojenie stanowi tylko pewien odsetek całości. Jest on jednak istotny z kilku powodów. Po pierwsze ilość i niezwykłość zgromadzonych przedmiotów dobitnie świadczy o potędze i możliwościach finansowych Radziwiłłów. Znaczenie kolekcji z Nieświeża jest symboliczne, począwszy od jej założenia, zapewne gdzieś w pierwszej połowie XVI w., lub nawet wcześniej, aż do likwidacji zainicjowanej w latach 1926-1927 przez ordynata nieświeskiego księcia Albrechta Radziwiłła (I885-1935). Rzecz jasna poszczególne elementy zbrojowni nieświeskiej przetrwały w różnych muzeach i zbiorach prywatnych, jednak sama kolekcja przestała istnieć. Po drugie, liczne grabieże, których dokonano na wszystkich zbiorach radziwiłłowskich, oraz przemieszczenia artefaktów między siedzibami rodowymi, spowodowały zmianę pierwotnego stanu posiadania poszczególnych osób. Kolekcje broni nie narastały więc tylko i wyłącznie w kolejnych pokoleniach, nie były to zbiory stałe. Częściowo je uzupełniano, przemieszczano, sprzedawano i tracono. Po trzecie wreszcie, jak słusznie zauważyłZdzisław Żygulski jun. (1982: 202) [...] obokjagiellońskiej, byta to najbogatsza zbrojownia Rzeczypospolitej w okresie renesansu. Powstawata na pewno jako wynik wspótzawodnictwa kolekcjonerskiego z królem, a nie bez wptywu byta też podobna rywalizacja z księciem Albrechtem pruskim, znakomitym znawca militariów. Badacz pisał oczywiście o zbrojowni nieświeskiej, która była jedną z kilku radziwiłłowskich. W momencie publikacji swego dzieła krakowski historyk sztuki był przekonany, że nie zachowały się żadne ślady po wczesnym etapie istnienia zbiorów. Za podstawowy przekaz uznawał prace z początku xx w. (Ehrenthal 1900-1902; Bersohn 1904) oraz katalogi aukcyjne z lat 1926 i 1927 (domu aukcyjnego Christie), a także zachowane w wielu muzeach zabytki.

Inwentarze radziwiłłowskie zostały już odnotowane w literaturze, poddane również były wstępnym badaniom. Godną uwagi pozycją jest praca historyka sztuki Tadeusza Bernatowicza (1998: 10, 17, 23-26), który zestawił spisy odnoszące się bezpośrednio do rezydencji nieświeskiej oraz wykorzystał pewne zawarte w nich informacje. Jeśli jednak chodzi o uzbrojenie, to trzeba podkreślić, że autor skupił uwagę głównie na omówieniu zachowanych luf armatnich, które powstawały w odlewni nieświeskiej począwszy od schyłku XVI w. bądź były własnością Radziwiłłów. T. Bernatowicz skupił się głównie na zdobieniach oraz inskrypcjach wykonanych poprzez odlew wraz z lufą. Pozostałe elementy uzbrojenia odnotował zbiorczo. Armaty i odlewnie radziwiłłowskie omówił białoruski badacz Mikola Volkay (Volkay 20I5; Bołdyrew 2019). Kilka artykułów eksponatom pochodzącym z Nieświeża poświęcił Mariusz Cieśla (2009; 2012a; 2012b; 2013; 2015).

W zasadzie żaden z przywołanych badaczy nie odniósł się bezpośrednio ani do najstarszego, zachowanego inwentarza, który sporządzono w 1563 r. (Archiwum, sygn. I), ani do pierwszego, zawierającego informacje na temat uzbrojenia, spisanego w I569 r. (Archiwum, sygn. 2). Inwentarz z 1569 r. został sporządzony 
w specyficznym momencie, to znaczy w chwili przemieszczenia zbioru z Nieświeża do Czarnawczyc, co samo w sobie potwierdza „mobilność” zbioru i fakt, że dopiero z czasem Nieśwież stał się głównym miejscem deponowania zbiorów przez gałąź Mikołaja Radziwiłła „Czarnego” (I515-I565) i jego syna Mikołaja Krzysztofa Radziwiłła „Sierotki” (I549-1616).

Omawiany zabytek rękopiśmiennictwa jest podwójnym poszytem. Po pierwszej bowiem karcie inwentarza z 1569 r. wszyto składkę mniejszego formatu, będącą innym zestawieniem dóbr przeznaczonych do ekspedycji do majątku czarnawczyckiego. Mniejszy poszyt zapisano do połowy objętości, ostatnie karty są puste. Co prawda w nagłówku autor stwierdził, że Te klejnotij nieboszki Panieij zapisaniem $J e(\mathrm{~g}) o$ X(iażęcej) $M$ (oś)ciprzezpana Gandolfa do Czarnawczijc poslalem roku iśg Augusta 17 (Archiwum, sygn. 2: 2), lecz na ostatniej stronie, inną ręką, sporządzono notatkę Regestrz Klejnotow do Czarnawczyc postanych in Aug (gusto) is65 (Archiwum, sygn. 2: I4). Najprawdopodobniej drugi wpis jest o wiele późniejszy i z niewiadomych powodów stanowi omyłkę osoby opracowującej ten konkretny inwentarz. Dalszy ciąg poszytu stanowi już zupełnie inny wykaz (od s. Is), spisany trzecią ręką $i$ to właśnie w nim po raz pierwszy wykazano liczne elementy uzbrojenia (Archiwum, sygn. 2: 15-45). Do dziś zachowały się trzy, bez mała tożsame, kopie tego spisu. Wykazują one w zasadzie identyczny zespół przedmiotów, należących do zbiorów nieświeskich. Niestety, w oparciu o ten dokument nie można stwierdzić, czy zespół stanowił całość zbiorów, czy tylko jakąś ich część, którą właściciel zdecydował się przenieść do Czarnawczyc. Na podstawie datowania inwentarza można określić, że dysponentem był zapewne Mikołaj Krzysztof „Sierotka”.

Omawiany spis zawiera wykaz ponad 560 pozycji, przy czym dziewięć z nich to pary, zatem ogólna liczba wymienionego uzbrojenia jest nieco wyższa. Zbiór ten stanowi nieco ponad $40 \%$ wszystkich przedmiotów odnotowanych w omawianym inwentarzu. Ogólny ogląd zawartości tego zabytku pozwala określić, że już w początkowym okresie wzrostu potęgi rodu zbrojownia nieświeska pełniła ważną rolę. Jednocześnie należy pamiętać, że inwentarz sporządzono jeszcze przed podjęciem prac nad budową obecnie istniejącego kompleksu pałacowego. Zapewne rację ma $\mathrm{T}$. Bernatowicz twierdząc, że zinwentaryzowany zbiór przeniesiono do pozyskanych dóbr w Czarnawczycach właśnie w związku z podjęciem zakrojonych na szeroką skalę prac budowlanych. Budowa nowego kompleksu pałacowego była wynikiem fatalnego stanu starego, drewnianego dworu obronnego należącego do Mikołaja „Czarnego” (Bernatowicz 1998: I0).

Najliczniejszą kategorią zamieszczoną w inwentarzu są elementy uzbrojenia ochronnego: 107 zbroi lub ich fragmentów, 93 hełmy i 20 tarcz (łącznie 220). Aż 30 było siorcow pancerzowych, prócz nich zaś 26 zbroy czarnych barwyanych ze wszystkimi sztukami. Na uwagę zasługuje też karacyna na czarnym yaxamycie nitowana z rękawami, a przede wszystkim zbroya szmalcowana hecowana miesci na byaliem 
szturmbabem z bartemy pliachownic para (Archiwum, sygn. 2: 15). Wśród hełmów również widoczna jest przewaga uzbrojenia służącego raczej do walki niż ekspozycji, to jest między innymi 36 szturmhabow dopiesze (go) liudu szmalcowanych i 25 prylbickozackich (Archiwum, sygn. 2: 15).Z kolei tarcze stanowiły kategorię jednolitą, ponieważ reprezentowało je 20 tarcy husarskich $z$ orlami (Archiwum, sygn. 2: 18). Zapewne egzemplarze te przypominały tarczę przechowywaną w British $\mathrm{Mu}-$ seum (nr inw. I881,0802.138), która ma malowaną również stronę wewnętrzną.

Prócz tego zapisano I2 6 przedmiotów, które należą do uzbrojenia zaczepnego (najliczniejsza grupa to broń drzewcowa: 47 egzemplarzy). Inwentarz nie potwierdza dużego rozpowszechnienia halabard, skoro odnotowano ich jedynie pięć, do tego wszystkie były s herby, co zdaje się sugerować, że była to raczej broń reprezentacyjna, a nie bojowa. Natomiast liczebnie (2 I sztuk) górują oszczepy i sefeliny, czyli w zasadzie odmiany tej samej broni (Archiwum, sygn. 2: 16). Broń obuchową reprezentują 24 czekany i 4 kylofy, zapewne nadziaki (Archiwum, sygn. 2: 16). Dość liczną grupę stanowiła ręczna broń palna - były to jednak wyłącznie rusznice. Ale z drugiej strony trzeba odnotować, że sześć z nich miało zamki kołowe, co koresponduje z przypuszczeniem, że ten typ zamka był popularniejszy niż wcześniej zakładano w oparciu o analizę materiału wykopaliskowego lub egzemplarzy muzealnych (Bołdyrew 20I4: 84). Bardzo interesujący jest zapis dotyczący niezwykłej strzelby: rucznica krotka o dwie rurach w lozi zeliaznim y [z] zamkami (Archiwum, sygn. 2: 15). Ten niespotykany okaz krótkiej „dubeltówki” stanowi w skali wszystkich zbrojowni radziwiłłowskich tylko przedsmak przechowywanych w nich zabytków.

Kolejnych is przedmiotów to zbiór części rzędu końskiego i oporządzenia jeździeckiego, wśród którego warto zwrócić uwagę na 30 siodeł: włoskich, niemieckich (brunszwickich) i husarskich krytych aksamitem, safianem i kurdybanem. Na koniec warto wspomnieć o 98 proporcach, tureckim bębnie i komplecie skrzydeł husarskich.

Całość zbioru odnotowanego w inwentarzu, ze względu na swoją liczebność, mogła stanowić jednocześnie całość zbioru nieświeskiego, lecz równie dobrze mogła być jedynie wyborem przeznaczonym do konkretnego transportu. Niezależnie od tego, rozmaitość i bogactwo kolekcji zaskakuje z dwóch powodów. Po pierwsze, widać wyraźnie skłonność do gromadzenia zarówno okazów kosztownych, jak i czysto użytkowych, o zachodnioeuropejskiej, ale i orientalnej proweniencji. Już samo to świadczy o możliwościach rodu i nieprzeciętności zbioru uzbrojenia, słusznie uznanego przez Z.Żygulskiego jun. za swoisty fenomen kulturowy. Po drugie, ilość wykazanego uzbrojenia dowodzi, że zbrojownia nieświeska sięga swoimi korzeniami przynajmniej pierwszej połowy XVI w. Jest zatem starsza niż kojarzony dziś z Nieświeżem kompleks pałacowy, w którym kolekcję przechowywano aż do momentu jej wyprzedania. 


\section{Aneks}

W aneksie pominięto słowo „item” rozpoczynające każdy kolejny wiersz wpisu. We właściwej części inwentarza pominięto znak „|” (koniec wiersza w podstawie wydania) kończący wpis dotyczący konkretnej pozycji, zachowano go natomiast w obrębie poszczególnych wpisów. Nagłówki kolejnych partii wykazu oznaczono

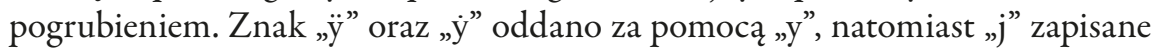
w podstawie wydania jako samogłoska (na przykład: między dwoma spółgłoskami, na końcu wyrazu po spółgłosce) oddano jako „i”. Znakom „v” i „u” w podstawie wydania przypisano współczesną wartość fonetyczną. Edycję przygotowano w oparciu o Projekt instrukcji wydawniczej dla pisanych źródet historycznych do potowy $X V I$ w. autorstwa Adama Wolffa (Wolff i957; Tandecki, Kopiński 2014: 328-354).

Zastosowane znaki edytorskie

| - koniec wiersza w podstawie wydania

[] - nawiasy wydawcy

() - nawiasy podstawy wydania

$[s]$ - potwierdzenie wyrazu w podstawie wydania

[?] - wątpliwość w odczycie podstawy wydania

[s. nr kursywa] - numer nowej strony podstawy wydania

[-- - opuszczenie wydawcy

$[S . I]$

Reiestr skarbowy to iest opisanie | wszystkie(go) rynsthunku woiennego | [początek zapisu w lewej kolumnie] jako zbroy | kirisow | shtrzelby $\mid$ mieczow $\mid$ szefelinow | puklerzow [koniec zapisu w lewej kolumnie] | [początek zapisu w prawej kolumnie] szat, ochędostwa rozneg(go) | y ynnych cudzoziemskie(go) | stroiu rynsthunkow | kobiercy kilimow | czego iest barzo wiele [koniec zapisu w prawej kolumnie]

Y drugi reiestr zlota srebra | kleinotow ss czego iest | staroswiczkemi nazwiski barzo|wiele

Y trzeci reiestr kleinotow Xiezny I(eij) M(oscij) | w roku 569 przepisanych y do | Czarnawczyc odesłanych z Nieswie|za przez P(ana) Gandolfa

$[--]$

[S.IS]

W komnacie te rzeczy złożone były

zbroy czarnych barwyanych ze wszystkimi sztukami 26

kierysi pobieliane 2 
polukierisie pobieliane I

roszkop na glowę konską I

zbroy kolczych do gonithwy 2

roszkopow na glowy końskie 2

szturmhabow ${ }^{1}$ do piesze(go) liudu szmalcowanych 36

szturmhabow z nosami do yezne(go) liudu szmalcowanych 13

szturmhabow miescy pozlocystych 2

szturmhabow poliorowanych do piesze(go) liudu 9

szturmhab zawarty szmalcowany I

pancerzow barwyanych is

zarękawj pancerzowych is

siorcow $^{2}$ pancerzowych z liacami 30

pancerz drobne(go) kolka s krótkimi rękawy u które(go) przędzele szrzebrnych 3

haciele I | paski z bliaszkami u pukliami srzebrnymi

zarękawie pancerzowe drobne(go) kolka krótkie s cikliami mosyądzowymi I

pludry pancerzowe drobne(go) kolka u których liać pancerzowy u które(go) przę-

dziele srze|brnych 2 haczlei s paskami 2

lissć $[s]$ pancerzowy I

oboyczyk pancerzowy kolka nienitowane(go) I

sztuka pancerza drobne(go) kolka s cykliami mosziądzwymi

karacyna na czarnym yaxamicie nitowana z rękawami I

zbroya szmalcowana hecowana miesci na byaliem alturmhabem z bartem y pliachownic para I

szyszaków 7

prylbic ${ }^{3}$ kozackich 25

karwaszy 2

roszkopow na glowy końskie 8

czapek yedwabnych czarnych $s$ kagancy pobielianymi I2

czapek yedwabnych czarnych s kaganci karzonymi 9

\section{Rucznicy y kiliofi}

rucznicz s kolami ${ }^{4}$ długich 5

rucznica s kolem dluga kosczią oprawyona I

rucznic długich hubczastich 4
1 Szturmaki.
2 Szorce.
3 Przyłbic.
$4 \mathrm{Z}$ zamkami kołowymi. 
rucznic krótkich $[\mathrm{z}]$ zamkami koscią oprawionych 4 rucznica krotka o dwie rurach w lozi zeliaznim y zamkami I rucznic krótkich w prostych lozach 6

$[s . I 6]$

rusznic w prostym lozu krótszych 6

kiliof zeliazny z rucznicą y zamkiem I

kiliof pozłocisty miesci y $[\mathrm{z}]$ syeierką I

kiliof zeliazny hecowany I

kiliof zeliazny czarno szmalcowany I

czekanow 24

aliabartow $\mathrm{z}$ herby 5

\section{Szefeliny y puklierze}

szefelin hecowany s kutasami yedwabiu czyrwone(go) y ze zlotem I

szefelin długie(go) zeliaza rogaty I

szefelin na xtalt karaska s forbotą 5 czarną yedwabną I

szefelin nie nasadzony I

oszczepów barwyanych 17

puklierz na czarnym yaxamicie s czyrwoną forbotą s promienmi zeliaznymi pozlocistimi | y z miesięcy y z gwiazdami I

puklierz pobieliany I

\section{Mieczyki y pasy}

mieczyk szmalcowany w rzemiennych poszwach I

mieczyk pobieliany w rzemiennych poszwach I

miecz wielki szmalcowany w rzemiennych poszwach I

szpada miescy pozlocista s pasem y s puynaliem I

kordek szmalcowany w [rz]yemiennych poszwach I

puynal ${ }^{6} \mathrm{~W}$ axamitnych poszwach $s$ pozliotką y srebrem nakrapiany s pasem I forimęt ${ }^{7}$ do szpady hecowany pozlocystj y z glowicą I

\footnotetext{
5 Forbota - koronka pleciona [...] z nitek ztotych, srebrnych lub jedwabnych [...], zob. Stownik polszczyzny... 1973, t. viI: 95. Frędzla.

6 Puginat.

7 Furdyment, fordyment - kosz (jelec koszowy) broni siecznej/kolnej, zob. Encyklopedia... 1901: 162 (z niem. Vorderhand); Stownik staropolski... (ok. 1920): 75 (z wł. guardamano); Kitowicz 1925: 300 (wymyślono do szabel takie krzyże, że catą rękę okrywaty; i zwat się taki krzyż furdyment, sktadat się z prętów żelaznych jak klatka i z blachy w środku wielkości dtoni); Gradowski, Żygulski 2000: 5.
} 
puynal pozłocisty w axamitny poszwach I

puynal nieoprawiony w pargaminie I

pas do miecza axamitny s cętkami szmalcowanymi I

pas do spady axamitu zolte(go) wzoriste(go) I

pas do szpady axamitu zolte(go) gładkie(go) I

pas do szpady axamitny czarny s cętkami pozłocistymi I

pas do szpady axamitu szare(go) s cętkami mosiądzowymi szmalcowanymi I

paski 2 krotkie do dwu szpad axamitne s cętkami pozlocistimi

prochownica koscyana pozlocista bez sznura I

prochownica szmalcowana [ze] sznurem I

prochownica na xtalt fliaszkj axamitem czarnym krita [ze] sznurem I

ladunki yedne pozłociste drugie proste 2

ostrog pozlocistich y niepozlocystich roznych par 8

$[s .17]$

Siodla

siodlo wloskye axamitu czarne(go) z lękami bliachowymi pozlocystymi I

siodlo wloskye axamitu byale(go) z lękami bliachowymi pozlocystimi I

siodlo wloskych [s] axamitu czarne(go) z lękami bliachowymi pozłocistymi 3

siodlo wloskye axamitu czarne(go) zlotymi sznurkami haftowane I

siodlo wloskie axamitu czarne(go) stare(go) I

siodel wloskych kurdwano(wy)ch yaxamitem bramowanych z lękami blyachowymi

| szaro kurzonymi 3

siodlo wloskye safianem czarnym krite s forbotą yedwabyu brunatne(go) z lękami

| wybyanymy $[\mathrm{w}]$ quyaty $^{8} \mathrm{I}$

siodel brąszwickich barwyanych starych skórą czarną powlieczonych z lekami ${ }^{9} \mid$

bliachowymi szaro kurzonymi 6

siodlo wloskye stare debyane ${ }^{10} \mathrm{I}$

siodel husarskich safianem kritych 6

\section{Rzędy}

rząd yaxamitu czarne(go) s forbotą sznurkami srebrnymi y s kutasami I

rząd yaxamitu czyrwone[go] s cętkami pozłocistymi I

rząd yaxamitu czarne(go) haftowany zlotymi y sreb[r]nymi sznurkami I

rząd haxamitu czarne(go) okręcony zlotymi sznurkami I

\footnotetext{
8 Kwiaty.

9 Łękami.

10 Dębowe, terlica dębowa?
} 
rząd yaxamitu czarne(go) s forbotą yedwaby[u] czyrwone(go) y ze zlotem I rzedy yaxamitu czarne(go) s paskamj y cętkami pozlocystymi nabyyane 2 rzędow yaxamitu czarne(go) cętkami pozlocystymi nabiyane 5

rząd yaxamitu czarne(go) stary s forbotami I

rzędow bliachowych barwyanych io

uzda yaxamitu czarne(go) turecka z mąsztukiem I

uzdyenica rzemienia byale(go) turecka I

mąsztukow ${ }^{11} 3$

pukliow do mąsztukow par 6

strzemion pozlocystych par 8

ostrog husarskich pozlocystych para I

dek na kon husarsky haftowany zlotymi srebrnymy sznurkami axamitu yatlasy | roznymi $s$ forbotą dlugą suknem czyrwonym podszyty I

przykrycie axamitu czyrwone(go) na woylok pod siodlo husarskie haftowane axamitami | roznymi y sznurkami zlotymi i srebrnymi y talietą ${ }^{12}$ zoltą ze zlotem I podkladaczow na zadny lęk husarskich bramowanych yąxamitem [s] czarnym 4 pokrowiec maliowany na siodlo mamalickye ${ }^{13} \mathrm{I}$

wezglowko axamitu czyrwone(go) haftowane I

skrzydla axamitu czyrwone(go) haftowane zlotymi sznurkami para I

$[s .18]$

$[-]$

sahaydak tatarsky [z] strzałami I

lukow tureckich 2

$[-]$

tarczy husarskich z orlami 20

drzewiec brąszwickych czarnych 2I

$[-]$

[s. 2o]

proporców husarskich kitayki bialey y czarney par 6

proporce husarsky czarney kitayki dlugi I

proporców husarskich hrasu [?] czarne(go) par 46

proporców husarskich zoltey kitayki par 3

proporców husarskich harasu czirwone(go) y plotna kolienskie(go) bialie(go) par I2

\footnotetext{
11 Munsztuki.

12 Taftą?

13 Mameluckie.
} 
proporce $[s]$ husarski czarney y byalei kytayki I

proporci husarskie maliowane s kitaiki bialey y czarney 2

proporec $[s]$ brąszwicki kytayki bialey czarney y czirwoney 2

proporczikow brąszwickych kytayki czarney s kutasikami bialimi 24

$[--]$

proporec $[s]$ do trąby s kitayki bialey czarney y czyrwoney I

znak hetmański kitayki bialey czarney y zoltey I

koszul kolienskich pod pancerz wisziwanich yedwabiem czarnym 3

$[--]$

$[s .2 I]$

bęben turecki I

\section{Bibliografia}

\section{Źródła}

Archiwum Główne Akt Dawnych w Warszawie, Archiwum Warszawskie Radziwiłłów, Dział Xxvi: rejestry skarbców i wszelakiego ruchomego majątku, sygn. I, 2.

\section{Opracowania}

Bernatowicz T. (1998), Monumenta variis Radivillorum. Wyposażenie zamku nieświeskiego w świetle źródet archiwalnych, cz. I, XVI-XVII wiek, Bogucki Wydawnictwo Naukowe, Poznań.

Bersohn M. (1904), Dawna zbrojownia ksiażą Radziwittów w Nieświeżu, b.w., Warszawa.

Bołdyrew A. (2014), The Armament of Polish Mercenary Infantry in the First Half of the I $6^{\text {th }}$ century, „Fasciculi Archaeologiae Historicae”, 27, s. 79-85.

Bołdyrew A. (2019), Studies on the Jagellonian and Polish-Lithuanian Commonwealth Artillery (a Side Note on Mikola Volkay's Artylerya Nassvishskaga zamka), „Fasciculi Archaeologiae Historicae", 32, s. 237-24I, https://doi.org/10.23858/FAH32.2019.016

Cieśla M. (2009), Zbrojownia Radziwittów z Nieświeża i broń związana z Polska w Metropolitan Museum of Art w Nowym Jorku, „Studia i Materiały do Historii Wojskowości", 46, s. 23-54.

Cieśla M. (2012a), Kunz Lochner ptatnerz królów i książą renesansu, „Prace Komisji Historii Wojen i Wojskowości PAU", 8, s. 153-167.

Cieśla M. (20I2b), Zbrojownia Radziwittów z Nieświeża i broń związana z Polska w Zbrojowni Higgins'a w Worcester, Philadelphia Museum of Art i The Fitzwilliam Museum w Cambridge, „Studia z Dziejów Wojskowości”, I, s. 43-65. 
Cieśla M.(2013), Zbrojownia Radziwittów - ostateczny upadek, „Studia z Dziejów Wojskowości", 2, s. 9-3I.

Cieśla M.(2015), Napierśnik i naplecznik kostiumowy z Muzeum Wojska Polskiego w Warszawie na tle zbroi tego typu, „Studia z Dziejów Wojskowości”, 4, s.9-55.

Ehrenthal M.(1900-1902), Die fürstlich Radziwillsche Rüstkammer zu Nieświez, „Zeitschrift für Historische Waffenkunde", 2, s. 142-145, 221-223, 276.

Encyklopedia staropolska ilustrowana (190I), t. II, Druk. P. Laskauera i W. Babickiego, Warszawa.

Głosek M.(2020), Początki i rozwój studiów bronioznawczych w Eodzi, [w:] T. Grabarczyk, M. Pogońska-Pol (red.), Oblicza wojny. Armia kontra natura, t. II, Wydawnictwo Uniwersytetu Łódzkiego, Łódź, s. 13-30, https://doi.org/10.18778/8220-057-7.02

Gradowski M., Żygulski jun. Z. (1998), Stownik uzbrojenia historycznego, Wydawnictwo Naukowe PWN, Warszawa.

Kajzer L. (2013), O meandrach polskiego bronioznawstwa stów kilka, [w:] P. Strzyż, W. Świętosławski (red.), Broń zwierciadtem epoki. Andrzeja Nadolskiego bronioznawcze dokonania i inspiracje, Łódzkie Towarzystwo Naukowe, Łódź, s. 13-2I.

Kitowicz J.(1925), Opis obyczajów i zwyczajów za panowania Augusta III, M.Janik (wyd.), Nakładem Krakowskiej Spółki Wydawniczej, Kraków.

Stownik polszczyzny XVI wieku (I973), t. vII, F - gończy, Zakład Narodowy im. Ossolińskich, Wrocław.

Stownik staropolski M. Arcta (ok. 1920), A. Krasnowolski, W.Niedźwiedzki (wyd.), Wydawnictwo M. Arcta, Warszawa.

Szymczak J. (2008), Pojedynki i harce, turnieje i gonitwy. Walki o życie, cześć, stawę i pieniądze w Polsce Piastów i Jagiellonów, Wydawnictwo Dig, Warszawa.

Tandecki J., Kopiński K.(2014), Edytorstwo źródet historycznych, Wydawnictwo DiG, Warszawa.

Volkay M.(2015), Artylerya Nasvishskaga zamka, Minsk.

Wolff A. (1957), Projekt instrukcji wydawniczej dla pisanych źródet historycznych do potowy $X V I w$., „Studia Źródłoznawcze”, I, s. I55-184.

Żygulski jun. Z.(1982), Broń $w$ dawnej Polsce na tle uzbrojenia Europy i Bliskiego Wschodu, Państwowe Wydawnictwo Naukowe, Warszawa.

\section{Summary}

This article descibes Nieśwież armoury (owned by Radzivills) in the half of $\mathrm{I} 6^{\text {th }}$ century. Main source is inventory listed in 1569 . In this inventory over 500 elements of arms and armour are mentioned. Among other them 220 defensive weapon, 126 offensive weapon (47 times polearm) and is elements of rider's equipment. In 1569 Radzivill's armoury contains plate armours, helmets, shields, spears, halberds, battle-axes, black-powder handguns and italian, german and oriental saddles with velvet, leather or cordovan overlay. 
Keywords: Polish-Lithuanian Commonwealth, Radzivills armoury, Nieśwież castle, inventory of 1569

\author{
Aleksander Bołdyrew \\ Uniwersytet Łódzki \\ Instytut Historii \\ Katedra Historii Średniowiecznej \\ e-mail: aleksander.boldyrew@uni.lodz.pl
}

Cc.coative

(C) by the author, licensee University of Lodz - Lodz University Press, Łódź, Poland. This article is an open access article distributed under the terms and conditions of the Creative Commons Attribution license CC-BY-NC-ND 4.0 (https://creativecommons.org/licenses/by-nc-nd/4.0/) 